\title{
Service Evaluation of Relaxation Workshops for Pregnant Women
}

\author{
Mo Tabib, MSc, BSc (Hons.), RM \\ Susan Crowther, PhD, MSc, BSc (Hons.), RM, RN
}

\begin{abstract}
This article reports a service evaluation of "antenatal education on physiology of childbirth and relaxation." A service evaluation was carried out during group class discussion, immediately after the workshops, and following birth. Identified themes in the collected data were (a) my own relaxation, (b) confident, and not afraid, (c) proud of myself, (d) unexpected and feeling in control, and (e) support. Overall, women creatively customized the learned skills and reported feelings of pride and confidence. They reported feeling able to apply relaxation techniques when unexpected situations arise. Support and encouragement from partners and midwives were also valued by women. The evaluation demonstrates the efficacy of designing antenatal education that includes education on physiology of normal birth and relaxation training.
\end{abstract}

The Journal of Perinatal Education, 27(1), http://dx.doi.org/10.1891/1058-1243.27.1.10 Keywords: relaxation, antenatal education, labor, birth

\section{INTRODUCTION}

It is not uncommon for pregnant women to experience some degree of anxiety and fear related to childbirth. It has been reported that up to $20 \%$ of women experience considerable childbirth fear (Salomonsson, Berterö, \& Alehagen, 2013). This is of concern because fear can influence childbirth outcomes. For example, fear of childbirth (FOC) has been connected with increasing obstetric interventions and is one of the most common reasons for requesting a cesarean (Handelzalts et al., 2012; Kringeland, Daltveit, \& Møller, 2009). FOC has also been reported as a predictor for psychological trauma and a risk factor for negative birth experience (Cheung, Ip, \& Chan, 2007; Keogh, Ayers, \&
Francis, 2002; Nilsson \& Lundgren, 2009; Soet, Brack, \& DiIorio, 2003; Waldenström, Hildingsson, \& Ryding, 2006). Emergent evidence over the last two decades has found a link between women's perception of control during childbirth and feelings of satisfaction with the experience (Cheung et al., 2007; Christiaens \& Bracke, 2007; Elmir, Schmied, Wilkes, \& Jackson, 2010; Oweis, 2009). It would appear that women's sense of control in childbirth is linked with positive feelings such as satisfaction, empowerment, and sense of achievement (O'Hare \& Fallon, 2011). There is a need to address FOC proactively if psychosocial and physiological outcomes are to be optimized. Antenatal classes incorporating education on the physiology of birth, and relaxation techniques 
may have a role in alleviating women's fear and anxiety (Downe et al., 2015; Werner, Uldbjerg, Zachariae, $\mathrm{Wu}, \&$ Nohr, 2013) and contribute to women feeling more control over their childbirth experiences (Levett, Smith, Bensoussan, \& Dahlen, 2016a).

\section{Physiology and Emotional Processes}

Physiology studies have demonstrated a range of emotional states such as fear causing sympathetic stimulation that in turn mobilizes the body for fight or flight (Waugh \& Grant, 2014). During childbirth, this fight or flight caused by the stimulation of the sympathetic system increases blood flow to the skeletal muscles and brain while withdrawing blood flow from nonvital organs including the reproductive systems (Waugh \& Grant, 2014).

In the 1950s Dick-Read argued that being in this fight or flight state during childbirth causes ischemia of the uterine muscle during labor (DickRead, 2013). Dick-Read presented the theory of Fear-Tension-Pain and argued that the sympathetic arousal during labor creates excessive tension in the lower segment of uterus which is recorded by nociceptors and interpreted as pain. Breaking the Fear-Tension-Pain cycle is a central concept in using relaxation techniques during childbirth, as these techniques could shift the balance of the autonomous nervous system towards a calmer state by reducing sympathetic activity, alleviate excessive pain, and contribute to a more positive experience of childbirth (Smith, Levett, Collins, \& Crowther, 2011).

Antenatal educational interventions aim to promote normality, contribute to psychosocial, emotional, and spiritual wellbeing, and improve experiences of childbirth (Crowther, 2014; Crowther, Smythe, \& Spence, 2014a; Gedde-Dahl \& Fors, 2012; Smith et al., 2011; Werner, Uldbjerg, Zachariae, Wu, \& Nohr, 2013). Emerging evidence supports relaxation techniques in childbirth and shows that when these techniques are employed by laboring women negative emotions, such as fear and anxiety, can be ameliorated while the relaxation itself contributes to feelings of self-confidence and satisfaction (Abbasi, Ghazi, BarlowHarrison, Sheikhvatan, \& Mohammadyari, 2009; Finlayson et al., 2015; Levett, Smith, Bensoussan, \& Dahlen, 2016b). There are several quantitative studies exploring the use of antenatal education interventions. However, these studies only employ
Emergent evidence over the last two decades has found a link

between women's perception of control during childbirth and

feelings of satisfaction with the experience.

a single technique such as, antenatal self-hypnosis training, and are inconclusive to demonstrate a significant reduction in the use of medical interventions such as pharmaceutical analgesia use or rate of cesarean surgery (Cyna et al., 2013; Downe et al., 2015; Werner, Uldbjerg, Zachariae, Rosen, \& Nohr, 2013). Some commentators suggest that introducing a "tool kit of skills" instead of one single technique may be more effective in pain management and working with pain during labor (Levett, Smith, Bensoussan, \& Dahlen, 2016a). It could be argued that an approach that offers a variety of techniques and strategies is more likely to be beneficial to a larger number of individuals compared with employing one single strategy. This multiple technique approach would promote the number of choices that women could make based on their personal preferences and situational demands and enhance the perceived feeling of control.

\section{An Evaluation of Services}

This paper reports on a service evaluation of antenatal relaxation workshops in National Health Service (NHS) Grampian in Scotland. The service was first developed in 2011 in addition to the routine care in response to a need and available expertise when there was an observed rise in the number of women with anxieties about childbirth who were requesting obstetric interventions in the absence of clinical indicators. It was vital from the start that any introduction of an intervention to the standard service required evaluation so that service development could be implemented according to local needs. The evaluation of the service included gathering the feedback of women on three occasions; (1) during the workshop, (2) immediately after the workshops, and (3) following their labor and birth experiences.

\section{The Workshops}

The aim of the workshops is to equip women with an understanding of physiology of childbirth and a variety of relaxation techniques to enable them to actively induce a calm state at will especially during 
pregnancy and labor. For the purpose of this paper, the term childbirth represents both the labor and birth.

The workshops are provided through collaboration between Robert Gordon University and NHS Grampian and are free of charge for the participants. The workshop is a one-off 3-hour workshop in addition to the routine antenatal education classes. Currently four sessions, maximum 8 hours, of antenatal education classes are routinely offered in pregnancy which include information on labor, birth, baby care, and becoming a parent. The information on the physiology of birth and relaxation techniques provided in the relaxation workshop does not overlap with the content of these classes. There are two workshops per month with the capacity of 12 women per session; birth partners are also welcomed to participate. Women who participated in the workshops were mostly those who had experienced and expressed a higher level of anxiety or apprehension of childbirth during pregnancy and therefore were referred mostly in the third trimester by their community midwives, obstetricians, or prenatal mental health team.

During the workshop, the physiology of natural birth based on the theory of Fear-Tension--Pain (Dick-Read, 2013) is discussed and birth stories from women who have used the techniques are shared. Almost half of the session is spent on the theory, storytelling, and group discussions. As Ickovics et al. (2003) suggest learning in groups has the advantage of improved learning, attitude change, motivation, and enhanced insight through sharing experiences. A positive language is employed that may positively impact the women's perceptions (Newberg \& Waldman, 2012); for instance, the term "waves" is frequently used instead of "pain or contractions." The workshops are facilitated and taught by a midwife/midwifery lecturer trained in relaxation techniques. Various exercises including breathing, visualization, muscle relaxation, and self-hypnosis are practiced to enable the participants to employ the techniques in accordance with their personal preferences and situational demands. Based on the six care practices supporting the normal physiological process of labor and birth identified by Lamaze (Lothian, 2014), through the workshops the concepts of latent phase of labor, adapting alternative and upright positions, and support during labor and birth are briefly discussed, and related to the physiology of normal birth. Handouts and an audio link are provided to facilitate further practice at home. Although one of the main aims of the workshop is to promote normal birth, the paramount importance of having a positive experience of childbirth is highlighted in the workshops and that a positive experience of childbirth could be achieved even if complications arise (Salomonsson et al., 2013). This strategy was employed in view of previous studies showing that women using selfhypnosis occasionally reported feeling frustrated or disappointed when their labor and birth experiences did not match their expectations (Finlayson et al., 2015). Therefore, the birth stories of women who, despite having complications and necessary interventions, had positive childbirth experience are shared. These birth stories are collected from previous participants and are presented to the class. Ethical approval for collecting the data was not required due to the report being a service evaluation; however, the permission for publication was sought from the Head of Midwifery in Grampian NHS.

\section{The Evaluation Process}

This was a service evaluation for a program of activity in which understanding of the intervention emerged from directly asking users of the service about their experiences. This approach sought to uncover what standard of experience this service provision was achieving. Various tools for data collection were employed:

1. group class discussions during the workshop,

2. anonymous evaluation forms completed at the end of the workshops,

3. collection of birth stories and feedback via email or phone interviews around 8 weeks following birth.

\section{FINDINGS}

The collected data presented in this paper is based on the class discussion and postworkshop questionnaire from 503 women who took part in the workshops between May 2014 and May 2016. However, the presented feedback on the childbirth experiences was collected only from 87 of the participants. These women were from various social backgrounds and ethnic groups with majority of them being White British. To protect the participants' anonymity, the 
names have been changed. The themes identified in the collected data were (a) my own relaxation, (b) confident, and not afraid, (c) proud of myself, (d) unexpected and feeling in control, and (e) support.

\section{Group Class Discussions}

The introduction at the beginning of the workshop and asking women about their motivation for participation almost always revealed a collective sense of apprehension towards labor and birth; particularly concept of "pain" in the group and a desire to overcome this, a desire for understanding it and working with it (Walsh \& Downe, 2010).

My Own Relaxation. Following each exercise women were asked to share their experiences of the exercise. It was striking to see how different these experiences were from one individual to another. The following are the comments from different women:

I felt much more relaxed and connected with my baby when we practiced the breathing exercise, did not feel the visualization as much.

I can so vividly see myself sitting on the beach, touching the soft sand, and smelling the ocean spray. ...

I could not see anything, but I could hear the ocean waves so clearly.

Some enjoyed only the breathing techniques, some preferred the guided imagery, and even between those who preferred the latter, there were differences in the way they experienced it. These differences were acknowledged and validated by the facilitator, and participants were encouraged to choose their preferred techniques and personalize their own individual strategies rather than following rigid instructions. The participants appreciated this approach and found it reassuring to use in the way that suits them. The women's feedback following birth also revealed women had creatively customized the relaxation techniques during labor and birth.

\section{Anonymous Evaluation}

The second stage of evaluation was gathering of anonymous feedback of the service through questionnaires. In these questionnaires, distributed at the end of the workshop, women were asked the following five questions:

1. Did you find the workshop useful?
2. What did you like/dislike about the workshop?

3. Would you recommend the workshop to others?

4. Any other comments?

5. Would you like to be contacted after birth to share your experience?

All women participating in the workshops commented on the anonymous evaluation forms that they found the workshop useful and would recommend it to other pregnant women. Around $85 \%$ of participants agreed to be contacted following the birth of their baby to provide feedback on their experiences.

More Confident and Not Afraid. The second theme generated through the questionnaire was confident, and not afraid. The open-ended question in the form asked women if they had any comments on the content of the workshop. The answers to this revealed the education of the physiology of birth, along with experiencing the ability to induce a relaxed state, created a new understanding of childbirth. An understanding that during labor, being in a fight or flight state will not be helpful, and in fact it is the dampening of the sympathetic response that will facilitate the physiology of birth. Experiencing the ability to induce a calm and relaxed state by employing simple techniques such as controlled breathing, or visualization, created a feeling of confidence in their own ability to shift the body balance from a fight or flight state to a calm and connected one. It seems this understanding, along with confidence, helped the women feel not afraid and more prepared towards the upcoming birth:

Now I know what will be going on (during labor) and I can do something about it,

there is no need for fear really if you know what is happening in your body,

I feel more confident now.

\section{Feedback Following Birth via Email or Phone Interviews}

The theme of feeling more confident continued to emerge in the contacts following birth. Marta, following the birth of her second child, says:

Going through the background information in class made so much sense to me especially the discussion 
around the panic/build-up of pain which I experienced with my first baby. I had none of that this time (second birth) which obviously helped me through the labor. Just wish I had been told about these things first time around.

Not all women had the same response to the workshops. For example, Emma did not use the techniques but her feelings of fear and apprehension towards childbirth were altered:

I didn't practice it and I didn't use it, but one thing changed for me after the class, I had this nightmare almost every night, waking up in tears saying to John my due date will be the last day of my life; that was why the midwife sent me to the class. You know, the class switched the way I was thinking about giving birth, that was the biggest thing, when contractions started I wasn't terrified or digging my grave, I was happy!

It is not clear what element in the workshop could cause these changes; whether it was the understanding of the physiology of labor, or stories of success, the language used, or visualizing the contractions as the ocean waves, or perhaps a combination of all of these. The causation of reduction in fear and increase in confidence remains unknown; however, a subtheme that continued to be revealed was how viewing contractions as helpful enabled women not to be afraid of them. Angela explains:

Throughout each contraction I kept thinking about what was said in the class that each pain was your body's way of bringing your baby one step closer to arriving in the world and was a good thing and not to be feared.

Women in this evaluation reported feeling confident to stay at home and not to seek hospitalization for the first hours of labor. Faye says:

I was focusing on breath during contractions and relaxing myself at home; then contractions slowed down and came back quite irregular but still bearable at home with my husband. This situation lasted for 2 days.

When the women commented on their ability to cope with labor and pain, and when they managed to avoid pharmaceutical pain reliefs, a sense of achievement and a feeling of pride in their ability to cope with intense pain were evident.
This is significant as research shows this could reduce early and unnecessary interventions (Tilden, Lee, Allen, Griffin, \& Caughey, 2015).

Proud of Myself. When the women commented on their ability to cope with labor and pain, and when they managed to avoid pharmaceutical pain reliefs, a sense of achievement and a feeling of pride in their ability to cope with intense pain were evident. Mia, a first-time mom, who had a home birth says:

I was not expecting that much pain, pain that I've never experienced in my life, but now that I think about it, it was a good experience. I think I was shocked with the amount of pain I was in, it was good. I only used gas and air along with breathing, I didn't panic, it was great. I was really surprised, 'cause I did have morphine in the fridge if I needed to, but I didn't want to, so it was really hard, but it felt like I could do this, and I did! . . When I think about it now I can't believe I did it, it was a huge thing in my life.

Although she described the experience as extremely painful, and despite having access to the pain relief, she chose not to take it and she was proud of her strength and achievement. During listening to and reading women's birth stories, the notion of difficulty and hardship of labor showed itself repeatedly. Women described the experience as "unbelievably painful" and "very hard" yet satisfaction with the experience of childbirth was consistently evident in the data. The notion of feeling good in childbirth despite experiencing difficulty and pain appears to be in contrast with a mechanical and medicalized understanding of the meaning of childbirth as painful and unpleasant (Olsson, Jansson, \& Norberg, 2000).

Unexpected and Feeling in Control. Some women reported experiencing unexpected complications both during pregnancy and childbirth such as need for induction of labor, diagnosis of fetal abnormalities through ultrasound scans, fetal distress, and emergency cesarean surgery. These women had felt able to utilize the learnt techniques at the time and described a feeling of being in control. Feredrica describes how this was crucial in the unpredictability of childbirth:

As my pregnancy progressed I developed some complications due to baby's position and I had excess of 
fluid. I had to attend lots of appointments at the hospital then, I found using the techniques very helpful to feel calm at a time when things were uncertain.

Leona, who had planned a water birth, following developing high blood pressure at 38 weeks and being admitted to an antenatal ward at the hospital:

My plans went out of window when my community midwife said, "Your blood pressure has gone up" and sent me to the hospital. . . the morning when they realized I was fully dilated in the antenatal ward, they panicked, but even then I felt in control. I didn't get my wish to give birth in the pool, yet it didn't matter coz I realized if I was in control it didn't matter where it happened.

It seems being in control irrespective of mode of birth and experiencing unexpected complications are likely to give rise to positive consequences relating to coping, self-sufficiency, and self-esteem.

Support. Attitude of midwives and birth partners seems to have a profound effect on women's perceptions of their own ability to utilize the learned skills. Women seem to vividly remember the encouraging words they received from the midwives as Amy describes:

The midwife commented that she had never seen someone look more like they were on morphine without actually having it at the time!

Conversely, Becky describes how discouraging attitudes also impacted her perceptions of self-belief and the decisions she made during childbirth:

I imagined how it looked at sunset, the sounds I would hear while there, and the hammock where I would be lying while taking it all in and got in a rhythme when I was reminded by the midwife that my labour may carry on for significanly more hours. I didn't feel I had the energy to focus on ignoring the pain for that much time and called for an epidural.

For Sarah, the midwife was able to facilitate using relaxation techniques by providing an environment of calm and support:

I had a fantastic midwife during labor who was incredibly supportive; even though I ended up in the labor ward she dimmed the light, and played my CD.
Debbie describes how experience of labor can be overwhelming yet a reminder from a partner can trigger the use of the learnt techniques:

I sat in the car, dashing to the hospital breathing frantically when he said, 'I thought you went to the relaxation classes!' and I realized, oh, yes I did go to them and remembered how it felt to be relaxed, so started my calm breathing and visualization.

Women's feedback provided an insight into the role of partners and midwives in encouraging, reminding, and facilitating the use of relaxation during the course of childbirth.

\section{DISCUSSION}

Evaluating the service through listening to women's feedback on their experiences of attending the workshops and their labor and birth experiences indicates that the workshops may have the potential to reduce fear and anxiety around labor and birth. The provided education intended to help participants develop an understanding of physiology of normal labor and birth, and be equipped with a "tool kit" of relaxation techniques that could facilitate this physiology. The findings of the service evaluation are congruent with the studies in confirming that offering such antenatal education could reduce women's fear and anxiety (Downe et al., 2015) and improve childbirth experiences (Levett et al., 2016b; Smith et al., 2011; Werner, Uldbjerg, Zachariae, Wu, $\&$ Nohr, 2013). It seems the combination of theory, experience, sharing experience, and employing an empowering and positive language may have positively impacted the women's perception of childbirth.

Offering a variety of relaxation techniques and encouraging individuality in choosing and creating the appropriate strategies for each woman seemed to make the workshops highly practical and beneficial for a wide population of women; out of 503 women participating in the workshops, all had related to the workshop in one way or another as revealed in the anonymous evaluation forms. According to the women's account of their experiences, they had managed to develop the ability to customize the relaxation techniques to induce an inner-silence and turn down the disturbing and catastrophizing thoughts whenever and wherever needed during pregnancy and labor. Women's creativity in applying the relaxation techniques has 
been found in the literature (Finlayson et al., 2015; Levett et al., 2016b).

The moods we attune to at birth have been shown to be important, for example, attuning to fear can cover over possibilities (Crowther, Smythe, \& Spence, 2014b). Likewise, the women in this evaluation felt less fearful and open to possibilities in their birth experience, feeling more prepared and confident for the experience of labor and birth. Following birth, the women linked their feelings of satisfaction and empowerment with the ability of staying calm and in control throughout the labor and birth whether their experience met their expectations or not. They felt able to cope better with unexpected events such as emergency cesarean surgery by utilizing the learnt techniques. Karlström, Nystedt, and Hildingsson (2015) conclude women with a very positive birth experience related their experience to their own ability and strength, and Salomonsson, Berterö, and Alehagen (2013) highlight the importance of finding appropriate coping strategies prior to the onset of labor particularly for women with FOC.

Understanding what was going on during the latent phase of labor, and feeling confident to work with pain at this stage seemed to contribute to less hospitalization in early labor. This may have implications for both women and maternity services as a recent cost-effectiveness analysis of latent versus active labor hospital admission for medically lowrisk, term women (Tilden et al., 2015) revealed delaying admission until active labor resulted in a considerable reduction in using epidurals, cesarean surgery rate, and maternal deaths.

An interesting finding was that women's expression of severity of labor pain and difficulty of labor was not associated with negative experiences; in contrast, it was strongly linked with the perception of strength and empowerment. Women chose not to use pharmaceutical pain reliefs as long as possible and this resistance resonated a feeling of achievement. The women described childbirth as difficult yet empowering and leading to a sense of

An interesting finding was that women's expression of severity of labor pain and difficulty of labor was not associated with negative experiences; in contrast, it was strongly linked with the perception of strength and empowerment. achievement and feeling of pride in their ability to cope with intense pain (Callister, Khalaf, Semenic, Kartchner, \& Vehvilainen-Julkunen, 2003; Lundgren \& Dahlberg, 1998).

The women commented that the birth attendants and birth partners could play an encouraging and facilitating role in the use of the learnt techniques by reminding women or providing an atmosphere of quiet and support, equally they could discourage the feeling of being relaxed by not doing so. Birth partners' support and their participation in the experience has been acknowledged by women in the literature (Karlström, Nystedt, \& Hildingsson, 2015; Ntombana, Sindiwe, \& Ntombodidi, 2014). Support from health care professionals, particularly midwives, as well as birth partners, could have a profound impact on women's self-belief, decision-making, and experience during childbirth (Ntombana et al., 2014; Salomonsson etal., 2013).

Although many women experienced short labors, natural births, and managed to avoid pharmaceutical pain reliefs including epidurals, the quantitative evaluation of the labor and birth outcomes for the participants was not carried out at this stage due to the aim of the survey being a qualitative exploration of the participants' experiences of attending the workshops as well as the impact of the education on their labor and birth experiences.

\section{Strengths and Limitations}

The findings of the evaluation are limited especially because the data collected on the birth experiences is limited only to the women who responded to the invitation emails or contacted the workshop facilitators themselves; therefore, the view of the women who did not respond is not included, and this may have contributed to bias in the evaluation. There remains a paucity of evidence on women's experiences of receiving antenatal education on physiology of birth and relaxation techniques; and the impact of this education on their labor and birth experiences. This evaluation provides a valuable contribution to this area and a starting point for further in-depth qualitative and quantitative research.

\section{Implications for Practice}

The findings of the evaluation indicate that women valued and appreciated receiving the education around the physiological process of labor and learning the relaxation techniques. Making the service 
widely available within maternity services may contribute to increased service users' satisfaction, improve their childbirth experiences, and promote their mental wellbeing. An increased level of confidence experienced following participation in the workshop may prevent early hospitalization during labor and creates a tendency to avoid pharmaceutical pain reliefs which in turn may prevent unnecessary interventions. This may have workload and financial implications for maternity services. Support and reminders from birth partners and midwives seem to trigger and reinforce the use of the learnt techniques and feelings of relaxation, therefore providing similar education for these two groups may help them facilitate a more coherent environment of support for laboring women.

\section{CONCLUSION}

Providing antenatal education on the physiology of birth, along with offering a variety of relaxation techniques, may influence the mood in the birthing room by alleviating the negative perceptions and fear of childbirth. Employing relaxation techniques during labor and birth appears to be associated with "staying calm and in control" irrespective of the mode of birth and experiencing unexpected events. This evaluation reveals how an antenatal educational intervention promotes feelings of selfconfidence, being in control, and preparedness for the experience of labor and birth which contributes to improving satisfaction and empowerment following birth.

\section{ACKNOWLEDGMENTS}

We would like to thank the women who participated in the evaluation. We also acknowledge the support and contribution of the Robert Gordon University and NHS Grampian for providing the service; with particular thanks to Ms Janet Mcnicol; the Head of Midwifery in Grampian, who granted the permission for publishing the findings of the service evaluation.

\section{REFERENCES}

Abbasi, M., Ghazi, F., Barlow-Harrison, A., Sheikhvatan, M., \& Mohammadyari, F. (2009). The effect of hypnosis on pain relief during labor and childbirth in Iranian pregnant women. International Journal of Clinical and Experimental Hypnosis, 57(2), 174-183. http://dx.doi. org/10.1080/00207140802665435
Callister, L. C., Khalaf, I., Semenic, S., Kartchner, R., \& Vehvilainen-Julkunen, K. (2003). The pain of childbirth: Perceptions of culturally diverse women. Pain Management Nursing, 4(4), 145-154. http://dx.doi.org/ 10.1016/S1524-9042(03)00028-6

Cheung, W., Ip, W. Y., \& Chan, D. (2007). Maternal anxiety and feelings of control during labour: A study of Chinese first-time pregnant women. Midwifery, 23(2), 123-130. http://dx.doi.org/10.1016/j.midw.2006.05.001

Christiaens, W., \& Bracke, P. (2007). Assessment of social psychological determinants of satisfaction with childbirth in a cross-national perspective. BMC Pregnancy and Childbirth, 7(1), 26. http://dx.doi.org/10.1186/ 1471-2393-7-26

Crowther, S. (2014). Foregrounding spirituality and joy at Birth in Antenatal Education. International Journal of Childbirth Education, 29(4), 8-14.

Crowther, S., Smythe, E., \& Spence, D. (2014a). The joy at birth: An interpretive hermeneutic literature review. Midwifery, 30(4), e157-e165. http://dx.doi.org/10. 1016/j.midw.2014.01.004

Crowther, S., Smythe, L., \& Spence, D. (2014b). Mood and birth experience. Women and Birth, 27(1), 21-25. http://dx.doi.org/10.1016/j.wombi.2013.02.004

Cyna, A. M., Crowther, C. A., Robinson, J. S., Andrew, M. I., Antoniou, G., \& Baghurst, P. (2013). Hypnosis antenatal training for childbirth: A randomised controlled trial. BJOG: An International Journal of Obstetrics \& Gynaecology, 120(10), 1248-1259. http://dx.doi.org/ 10.1111/1471-0528.12320

Dick-Read, G. (2013). Childbirth without fear: The principles and practice of natural childbirth. London, UK: Pinter \& Martin Ltd.

Downe, S., Finlayson, K., Melvin, C., Spiby, H., Ali, S., Diggle, P., . . . Williamson, M. (2015). Self-hypnosis for intrapartum pain management in pregnant nulliparous women: A randomised controlled trial of clinical effectiveness. BJOG: An International Journal of Obstetrics \& Gynaecology, 122(9), 1226-1234. http:// dx.doi.org/10.1111/1471-0528.13433

Elmir, R., Schmied, V., Wilkes, L., \& Jackson, D. (2010). Women's perceptions and experiences of a traumatic birth: A meta-ethnography. Journal of Advanced Nursing, 66(10), 2142-2153. http://dx.doi.org/10. 1111/j.1365-2648.2010.05391.x

Finlayson, K., Downe, S., Hinder, S., Carr, H., Spiby, H., \& Whorwell, P. (2015). Unexpected consequences: Women's experiences of a self-hypnosis intervention to help with pain relief during labour. BMC Pregnancy and Childbirth, 15(1), 229. http://dx.doi.org/10.1186/ s12884-015-0659-0

Gedde-Dahl, M., \& Fors, E. A. (2012). Impact of selfadministered relaxation and guided imagery techniques during final trimester and birth. Complementary Therapies in Clinical Practice, 18(1), 60-65.

Handelzalts, J. E., Fisher, S., Lurie, S., Shalev, A., Golan, A., \& Sadan, O. (2012). Personality, fear of childbirth and cesarean delivery on demand. Acta Obstetricia et Gynecologica Scandinavica, 91(1), 16-21. http://dx.doi. org/10.1111/j.1600-0412.2011.01287.x 
Ickovics, J. R., Kershaw, T. S., Westdahl, C., Rising, S. S., Klima, C., Reynolds, H., \& Magriples, U. (2003). Group prenatal care and preterm birth weight: Results from a matched cohort study at public clinics. Obstetrics and Gynecology, 102(5 Pt 1), 1051-1057.

Karlström, A., Nystedt, A., \& Hildingsson, I. (2015). The meaning of a very positive birth experience: Focus groups discussions with women. BMC Pregnancy and Childbirth, 15(1), 251. http://dx.doi.org/10.1186/ s12884-015-0683-0

Keogh, E., Ayers, S., \& Francis, H. (2002). Does anxiety sensitivity predict post-traumatic stress symptoms following childbirth? A preliminary report. Cognitive Behaviour Therapy, 31(4), 145-155. http://dx.doi.org/ 10.1080/165060702321138546

Kringeland, T., Daltveit, A. K., \& Møller, A. (2009). What characterizes women in Norway who wish to have a caesarean section? Scandinavian Journal of Public Health, 37(4), 364-371. http://dx.doi.org/10.1177/ 1403494809105027

Levett, K. M., Smith, C. A., Bensoussan, A., \& Dahlen, H. G. (2016a). Complementary therapies for labour and birth study: A randomised controlled trial of antenatal integrative medicine for pain management in labour. BMJ Open, 6(7), e010691. http://dx.doi.org/10.1136/ bmjopen-2015-010691

Levett, K. M., Smith, C. A., Bensoussan, A., \& Dahlen, H. G. (2016b). The complementary therapies for labour and birth study making sense of labour and birthexperiences of women, partners and midwives of a complementary medicine antenatal education course. Midwifery, 40, 124-131. http://dx.doi.org/10.1016/j. midw.2016.06.011

Lothian, J. A. (2014). Promoting optimal care in childbirth. The Journal of Perinatal Education, 23(4), 174 177. http://dx.doi.org/10.1891/1058-1243.23.4.174

Lundgren, I., \& Dahlberg, K. (1998). Women's experience of pain during childbirth. Midwifery, 14(2), 105-110. http://dx.doi.org/10.1016/S0266-6138(98)90007-9

Newberg, A., \& Waldman, M. R. (2012). Words can change your brain: 12 conversation strategies to build trust, resolve conflict, and increase intimacy. Westminster, UK: Penguin.

Nilsson, C., \& Lundgren, I. (2009). Women's lived experience of fear of childbirth. Midwifery, 25(2), e1-e9. http://dx.doi.org/10.1016/j.midw.2007.01.017

Ntombana, R., Sindiwe, J., \& Ntombodidi, T. (2014). Opinions of labouring women about companionship in labour wards. African Journal of Midwifery and Women's Health, 8(3), 123-127. http://dx.doi.org/10. 12968/ajmw.2014.8.3.123

O'Hare, J., \& Fallon, A. (2011). Women's experience of control in labour and childbirth. British Journal of Midwifery, 19(3).

Olsson, P., Jansson, L., \& Norberg, A. (2000). A qualitative study of childbirth as spoken about in midwives' ante- and postnatal consultations. Midwifery, 16(2), 123-134. http://dx.doi.org/10.1054/midw.1999.0201

Oweis, A. (2009). Jordanian mother's report of their childbirth experience: Findings from a questionnaire survey. International Journal of Nursing Practice, 15(6), 525-533. http://dx.doi.org/10.1111/j.1440-172X.2009. 01774.x

Salomonsson, B., Berterö, C., \& Alehagen, S. (2013). Selfefficacy in pregnant women with sevee fear of childbirth. Journal of Obstetric, Gynecologic \& Neonatal Nursing, 42(2), 19112p-202. http://dx.doi.org/10. $1111 / 1552-6909.12024$

Smith, C. A., Levett, K. M., Collins, C. T., \& Crowther, C. A. (2011). Relaxation techniques for pain management in labour. The Cochrane Library, 12, CD009514.

Soet, J. E., Brack, G. A., \& Dilorio, C. (2003). Prevalence and predictors of women's experience of psychological trauma during childbirth. Birth, 30(1), 36-46. http:// dx.doi.org/10.1046/j.1523-536X.2003.00215.x

Tilden, E. L., Lee, V. R., Allen, A. J., Griffin, E. E., \& Caughey, A. B. (2015). Cost-effectiveness analysis of latent versus active labor hospital admission for medically low-risk, term women. Birth, 42(3), 219-226. http://dx.doi.org/ 10.1111/birt.12179

Waldenström, U., Hildingsson, I., \& Ryding, E. L. (2006). Antenatal fear of childbirth and its association with subsequent caesarean section and experience of childbirth. BJOG: An International Journal of Obstetrics and Gynaecology, 113(6), 638-646. http://dx.doi.org/10. 1111/j.1471-0528.2006.00950.x

Walsh, D., \& Downe, S. (2010). Essential midwifery practice: Intrapartum care: Wiley Online Library.

Waugh A., \& Grant A. (Eds.). (2014). Ross and Wilson anatomy and physiology in health and illness (12th ed.). Edinburgh: Churchill Livingstone

Werner, A., Uldbjerg, N., Zachariae, R., Rosen, G., \& Nohr, E. A. (2013). Self-hypnosis for coping with labour pain: A randomised controlled trial. BJOG: An International Journal of Obstetrics \& Gynaecology, 120(3), 3468p-353. http://dx.doi.org/10.1111/14710528.12087

Werner, A., Uldbjerg, N., Zachariae, R., Wu, C. S.,Nohr, E. A \& . (2013). Antenatal hypnosis training and childbirth experience: a randomized controlled trial. Birth, 40(4), 272-280. http://dx.doi.org/10.1111/birt .12071

MO TABIB has worked as a registered midwife across the two countries of the United Kingdom and Iran. She has a background of working as a community, hospital, research, and independent midwife. She is currently a midwifery lecturer at Robert Gordon University in Scotland. Her research interests include promoting normality in childbirth and implementing relaxation techniques in antenatal education and midwifery practice. SUSAN CROWTHER has worked across the United Kingdom, New Zealand, several African countries, and ex-Soviet regions in different roles. Susan has a background in caseload midwifery practice, consultant midwifery, education 
and research. Her research interests include phenomenological exploration of experiences connected to childbirth from different perspectives, spirituality in maternity, rural midwifery, and sustainable practice. She is on the editorial board of three peerreviewed journals, frequent reviewer and member of the Research Standing Committee of the International Confederation of Midwives. 